\title{
Arterial/alveolar oxygen tension ratio: a critical appraisal
}

A critical analysis of the arteriallalveolar oxygen tension ratio $\left(\mathrm{a} / \mathrm{APO}_{2}\right)$ is presented by rearranging the terms of the pulmonary shunt equation. The influence of the shunt and inspired oxygen concentration on a/APO $\mathrm{O}_{2}$ are illustrated. It is shown that, despite reports to the contrary, alAPO $\mathrm{A}_{2}$ varies with $\mathrm{FIO}_{2}$, particularly at high shunt levels.

In recent years, the arterial/alveolar oxygen tension ratio $\left(\mathrm{PaO}_{2} / \mathrm{PAO}_{2}\right)$, sometimes denoted a/APO , has developed a reputation as an index of gas exchange well-suited for use in pulmonary assessment and oxygen therapy. For example, while the alveolar/arterial oxygen tension difference $\left(\mathrm{A}-\mathrm{aPO}_{2}\right)$ is known to depend strongly on the fraction of inspired oxygen $\left(\mathrm{FIO}_{2}\right){ }^{\prime}$ this property has been reported to be absent for the a/APO thereby rendering it an index of gas exchange less dependent on extrapulmonary factors. ${ }^{2}$ In particular, the reputed stability of a $/ \mathrm{APO}_{2}$ across varying $\mathrm{FIO}_{2}$ levels has formed the basis for two reports concerning its use to predict $\mathrm{PaO}_{2}$ following changes in $\mathrm{FrO}_{2}{ }^{3,4}$ Similarly, Peris et al. ${ }^{5}$ found a/APO $\mathrm{A}_{2}$ to be useful "not only for predicting the arterial oxygen tension but also choosing the necessary oxygen supplementation." However, to date, it appears that a/APO $\mathrm{A}_{2}$ has only been examined empirically and that no study of the physiological factors affecting it determined from first principles

\section{Key words}

ARTERIAL/ALVEOLAR OXYGEN TENSION RATIO; a/APO ${ }_{2}$; pulmonary shunt.

From the Department of Anaesthesia and the Institute of Biomedical Engineering, University of Toronto, Toronto, Ontario, M5S 1A4. has been reported. Such a study is presented here. It is demonstrated that a/APO 2 does, in fact, have some dependence on $\mathrm{FIO}_{2}$, particularly at high levels of pulmonary shunt.

\section{Analysis}

Pulmonary shunt is an excellent measure of oxygen transfer properties of the lung which has been studied widely. The pulmonary shunt equation is well known:

$\mathrm{Qs} / \mathrm{Qt}=\left(\mathrm{CcCO}_{2}-\mathrm{CaO}_{2}\right) /\left(\mathrm{CćO}_{2}-\mathrm{Cv}_{2}\right)$

However, for notational simplicity, we will denote Qs/Qt as Z. By algebraic manipulation of the shunt equation, as shown in the appendix, it is possible
Glossary
a/ $\mathrm{APO}_{2}$ - arterial/alveolar oxygen tension ratio
$\mathrm{A}-\mathrm{aPO}_{2}$ - alveolar/arterial oxygen tension differ- ence $(\mathrm{mmHg}$ )
$\mathrm{CaO}_{2} \quad$ - arterial oxygen content (vol\%)
$\mathrm{Cc}_{2}-$ end pulmonary capillary oxygen content (vol\%)
$\mathrm{Cu}_{2}-$ mixed venous oxygen content ( $\mathrm{vol} \%$ )
$\mathrm{Ca}-\mathrm{vO}_{2}$ - arterial/mixed venous oxygen content difference (vol\%)
$\mathrm{FIO}_{2}$ - fraction of inspired oxygen
$\mathrm{Hb}$ - haemoglobin concentration (g/dl)
$\mathrm{PaCO}_{2}$ - arterial carbon dioxide ( $\mathrm{mmHg}$ )
$\mathrm{PaO}_{2}$ - arterial oxygen tension ( $\mathrm{mmHg}$ )
$\mathrm{PAO}_{2}$ - alveolar oxygen tension $(\mathrm{mmHg})$
$\mathrm{PB} \quad$ - barometric pressure $(\mathrm{mmHg})$
$\mathrm{PH}_{2} \mathrm{O}$ - water vapour pressure $(\mathrm{mmHg})$
$\mathrm{Qs} / \mathrm{Qt}(\mathrm{Z})$ - pulmonary shunt fraction
$\mathrm{R} \quad$ - gas exchange ratio
$\mathrm{SaO}_{2}$ - arterial oxygen saturation
$\mathrm{ScO}_{2}$ - end pulmonary capillary oxygen saturation
$\mathrm{SṽO}_{2}-$ mixed venous oxygen saturation 
to relate arterial oxygen tension to its influencing factors:

(1) $\mathrm{PaO}_{2}=\mathrm{PAO}_{2}-\left[\mathrm{Ca}-\overline{\mathrm{v}} \mathrm{O}_{2} \times \mathrm{Z} /(1-\mathrm{Z})\right.$

$$
\left.-1.34 \times\left(\mathrm{ScO}_{2}-\mathrm{SaO}_{2}\right) \times \mathrm{Hb}\right] / 0.0031
$$

where $\mathrm{PAO}_{2}(\mathrm{mmHg})$ is the alveolar oxygen tension, $\mathrm{Ca}-\mathrm{vO}_{2}(\mathrm{vol} \%)$ is the arterial/mixed venous oxygen content difference $\left(=\mathrm{CaO}_{2}-\mathrm{C} \overline{\mathrm{v}} \mathrm{O}_{2}\right), \mathrm{SćO}_{2}$ is end-pulmonary capillary fractional saturation, $\mathrm{SaO}_{2}$ is the arterial saturation and $\mathrm{Hb}$ is the blood haemoglobin concentration $\left(\mathrm{g} \cdot \mathrm{dl}^{-1}\right)$. The alveolar gas equation is used to determine $\mathrm{PAO}_{2}$ :

$$
\begin{aligned}
\mathrm{PAO}_{2}=\left(\mathrm{PB}-\mathrm{PH}_{2} \mathrm{O}\right) \times \mathrm{FIO}_{2}-\mathrm{PaCO}_{2} \\
\times\left[\mathrm{FIO}_{2}+\left(1-\mathrm{FIO}_{2}\right) / \mathrm{R}\right]
\end{aligned}
$$

where $\mathrm{PB}$ is the barometric pressure (assumed to be $760 \mathrm{mmHg}$ ), $\mathrm{PH}_{2} \mathrm{O}$ is the patient's water vapour pressure (assumed to be $47 \mathrm{mmHg}$ ), $\mathrm{PaCO}_{2}$ is the arterial $\mathrm{CO}_{2}$ tension (usually assumed to be $40 \mathrm{mmHg}$ ) and $\mathrm{R}$ is the gas exchange ratio (assumed to be 0.8 )

The arterial/alveolar $\mathrm{PO}_{2}$ ratio can thus be obtained by taking the ratio of equations ( 1 ) and (2) for specific choices of physiological variables. However, solving equation (1) is complicated by the need to introduce analytical relationships between $\mathrm{PAO}_{2}$ and $\mathrm{ScO}_{2}$, and $\mathrm{PaO}_{2}$ and $\mathrm{SaO}_{2}$. Kellman ${ }^{6}$ has developed a nonlinear analytical expression relating oxygen tension and saturation given $\mathrm{pH}, \mathrm{PCO}_{2}$ and temperature. This relation was used to obtain both $\mathrm{ScO}_{2}$ estimates from $\mathrm{PAO}_{2}$ and $\mathrm{SaO}_{2}$ estimates from $\mathrm{PaO}_{2}$ with the assumed levels of $\mathrm{pH}, \mathrm{PCO}_{2}$ and temperature being the same in both cases. (The usual assumptions were $\mathrm{pH}=7.4, \mathrm{PCO}_{2}=$ $40 \mathrm{mmHg}$, temperature $=37^{\circ} \mathrm{C}$.) The commonly used simplifying assumption of setting $\mathrm{ScO}_{2}$ equal to unity was avoided to provide for accuracy under conditions of low barometric pressure. Unfortunately, even with the Kellman equation, equation (1) is not easily solved because we are dealing with the solution of a set of two nonlinear equations (i.e., equation (1) and Kellman's equation). In the case of this study a computer-based successive approximation method was employed to obtain a solution. This amounted to iteratively making successively more accurate estimates of $\mathrm{PaO}_{2}$ levels which met both equation (1) and Kellman's equation. Equation (1) was solved in this way to an accuracy of $0.005 \mathrm{mmHg}$ for various values of $\mathrm{Hb}, \mathrm{Ca}-\overline{\mathrm{v}} \mathrm{O}_{2}$ and $\mathrm{FiO}_{2}$.

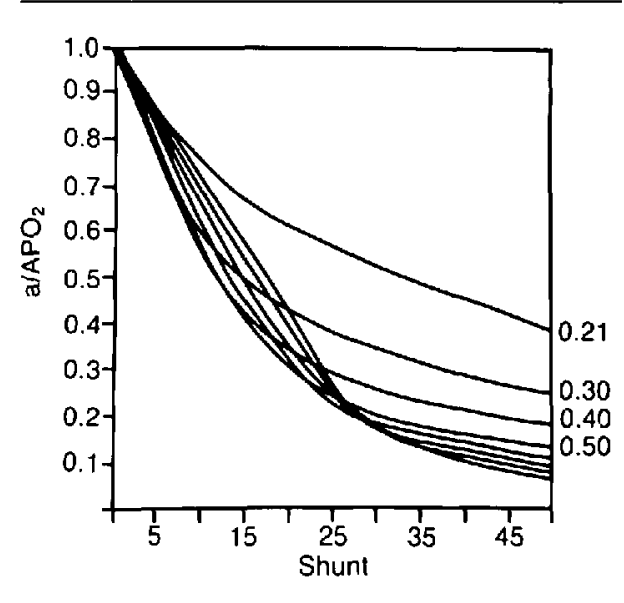

FIGURE Variation in arterial/alveolar $\mathrm{PO}_{2}$ ratio $\left(\mathrm{a} / \mathrm{APO} \mathrm{O}_{2}\right.$ with varying inspired oxygen levels $\left(\mathrm{FlO}_{2}\right)$ and various levels of pulmonary shunt. Here $\mathrm{Hb}$ is $150 \mathrm{~g} \cdot \mathrm{L}^{-1} \cdot \mathrm{Ca}-\overline{\mathrm{vO}} \mathrm{O}_{2}$ is $5 \mathrm{vol} \%$, $\mathrm{pH}$ is $7.4, \mathrm{PaCO}_{2}$ is $40 \mathrm{mmHg}, \mathrm{PB}$ is $760 \mathrm{mmHg}, \mathrm{R}$ is 0.8 , and body temperature is $37^{\circ} \mathrm{C}$. Note the strong dependence of a/ $\mathrm{APO}_{2}$ on $\mathrm{FIO}_{2}$ at high shunt levels. The table presents some of this data in more detail.

\section{Results}

The figure shows how a/ $\mathrm{APO}_{2}$ varies with pulmonary shunt for $\mathrm{FIO}_{2}$ levels of $21,30,40,50,60,70$, 80,90 , and 100 per cent and with $\mathrm{Ca}-\overline{\mathrm{v}} \mathrm{O}_{2}$ chosen to be 5 vol\% and $\mathrm{Hb}$ set to $150 \mathrm{~g} \cdot \mathrm{L}^{-1}$. Here, for a given $\mathrm{FIO}_{2}$, a $/ \mathrm{APO}_{2}$ always decreases with shunt, while for a given shunt, a/APO may vary in either direction with increases in $\mathrm{FIO}_{2}$. For example, for a patient with the above $\mathrm{Ca}-\overline{\mathrm{v}} \mathrm{O}_{2}$ and $\mathrm{Hb}$ values and with a five per cent shunt, when breathing room air the a/ $\mathrm{APO}_{2}$ will be 0.848 while at an $\mathrm{FIO}_{2}$ of 40 per cent the $\mathrm{a} / \mathrm{APO}_{2}$ will drop to 0.740 and on 100 per cent oxygen the a $/ \mathrm{APO}_{2}$ will rise to 0.875 . Similarly, with a 30 per cent shunt the a/ $\mathrm{APO}_{2}$ will be 0.525 on room air, 0.257 on 40 per cent oxygen and 0.163 on 100 per cent oxygen. As can be seen from the figure, variation of a/APO $\mathrm{A}_{2}$ with $\mathrm{FIO}_{2}$ seems to increase with shunt. In the table we present some of the data in more detail. Of particular interest is the observation that the ratio of maximum to minimum a/ $\mathrm{APO}_{2}$ values across the $\mathrm{FIO}_{2}$ values chosen increases with shunt, i.e., a/ $\mathrm{APO}_{2}$ varies more across $\mathrm{F}_{1} \mathrm{O}_{2}$ values with increasing shunt. Similar results were obtained for other haemoglobin and $\mathrm{Ca}-\overline{\mathrm{v}} \mathrm{O}_{2}$ values. Clearly, the data suggest that a/ $\mathrm{APO}_{2}$ may vary considerably with $\mathrm{FIO}_{2}$ under 
TABLE Detailed results of some of the data shown in the figure

\begin{tabular}{llllll}
\hline $\begin{array}{l}\text { Per cent } \\
\text { shunt }\end{array}$ & $\begin{array}{l}\text { alAPO } \\
21 \% \text { oxygen }\end{array}$ & $\begin{array}{l}\text { alAPO on } \\
\text { I00\% oxygen }\end{array}$ & $\begin{array}{l}\text { Minimum } \\
\text { alAPO }\end{array}$ & $\begin{array}{l}\text { Maximum } \\
\text { alAPO }\end{array}$ & $\begin{array}{l}\text { Maximin } \\
\text { ratio }\end{array}$ \\
\hline 5 & 0.848 & 0.875 & $0.740(40)$ & $0.875(100)$ & 1.18 \\
10 & 0.745 & 0.738 & $0.536(40)$ & $0.745(21)$ & 1.39 \\
15 & 0.670 & 0.587 & $0.386(50)$ & $0.670(21)$ & 1.74 \\
20 & 0.612 & 0.425 & $0.281(60)$ & $0.612(21)$ & 2.18 \\
25 & 0.565 & 0.268 & $0.207(70)$ & $0.565(21)$ & 2.73 \\
30 & 0.525 & 0.163 & $0.155(90)$ & $0.525(21)$ & 3.39 \\
35 & 0.489 & 0.117 & $0.117(100)$ & $0.489(21)$ & 4.18 \\
40 & 0.455 & 0.096 & $0.096(100)$ & $0.455(21)$ & 4.74 \\
45 & 0.422 & 0.083 & $0.083(100)$ & $0.422(21)$ & 5.08 \\
50 & 0.389 & 0.073 & $0.073(100)$ & $0.389(21)$ & 5.33 \\
\hline
\end{tabular}

Note that the variation of a/APO across $\mathrm{FtO}_{2}$ increases with shunt. Here $\mathrm{Ca}-\overline{\mathrm{v}} \mathrm{O}_{2}$ was set at 5 vol\% with a haemoglobin of $150 \mathrm{~g} \cdot \mathrm{L}^{-1}$. Values in parentheses given are per cent $\mathrm{FlO}_{2}$ values at which a maximum or minimum was found.

clinical conditions likely to be encountered in critically ill patients.

\section{Discussion}

The a/ $\mathrm{APO}_{2}$ ratio has been discussed widely in the critical care literature, but to date an analytical basis for understanding its behaviour with alterations of various physiological variables has not been available. Such an analysis based on the shunt equation is presented here. The widely held belief that a/APO $\mathrm{As}_{2}$ relatively independent of $\mathrm{FIO}_{2}$ is examined critically and is shown to be true only to a limited extent, particularly with large shunts. This is consistent with the later work of Gilbert et $\mathrm{al}^{7}$ who partially altered their original statements regarding alleged a/APO ${ }_{2}$ stability with $\mathrm{FIO}_{2}$ changes to point out that in critically ill patients a/ $\mathrm{APO}_{2}$ may change with $\mathrm{FIO}_{2}$, although less so than $\mathrm{A}-\mathrm{aPO}_{2}$.

The above notwithstanding, it is the author's belief that the a $\mathrm{APO}_{2}$ remains a clinically useful index of gas exchange when its limitations are appreciated. Although the a/APO $\mathrm{As}_{2}$ not independent of $\mathrm{FIO}_{2}$, it can be shown to be less dependent of $\mathrm{FlO}_{2}$ than the $\mathrm{A}-\mathrm{aPO}_{2}$, and on this basis alone it may be useful.

\section{References}

1 Torda TA. Alveolar-arterial oxygen tension difference: a critical look. Anaesth Intensive Care 1981; 9: 326-30.

2 Gilbert $R$, Keighley JF. The arterial-alveolar oxygen tension ratio. An index of gas exchange applica- ble to varying inspired oxygen concentration. Am Rev Respir Dis 1974; 109: 142-5.

3 Hess D. Prediction of the change in $\mathrm{PaO}_{2}$. Crit Care Med 1979; 7: 568-9.

4 Abizanda $R$, Lopez $J$. The possibility of predicting $\mathrm{PaO}_{2}$ following changes in $\mathrm{FIO}_{2}$. Intensive Care Med 1981; 7: 247

5 Peris LV, Boix JH, Salom JV et al. Clinical use of the arterial/alveolar oxygen tension ratio. Crit Care Med 1983; 11: 888-91.

6 Kellman $G R$. Digital computer subroutine for the conversion of oxygen tension into saturation. $J$ Appl Physiol 1966; 21: 1375-6.

7 Gilbert R, Auchincloss JH, Kuppinger $M$ es al. Stability of the arterial-alveolar oxygen partial pressure ratio. Effects of low ventilation-perfusion regions. Crit Care Med 1979; 7: 267-72

\section{Résumé}

Une analyse critique du rapport de la tenson d'oxygène artériellelalvéolaire $\left(a / \mathrm{APO}_{2}\right)$ est présentée en réarrangeant les termes de l'équation du shunt pulmonaire. Les influences du shunt et de la concentration d'oxygène inspirée sur le rapport alAPO $\mathrm{O}_{2}$ sont illustrées. Il est démontré que malgré les assertions contraires, les rapports alAPO $\mathrm{O}_{2}$ varient avec la $\mathrm{FlO}_{2}$ particulièrement à des niveaux de shunt élevés. 


\section{Appendix}

Derivation of equation (1):

$\mathrm{Z}(=\mathrm{Qs} / \mathrm{Qt})=\left(\mathrm{CcO}_{2}-\mathrm{CaO}_{2}\right) /\left(\mathrm{CćO}_{2}-\mathrm{CvO}_{2}\right)$

Let

$\mathrm{CùO}_{2}=\mathrm{CaO}_{2}-\mathrm{Ca}-\overline{\mathrm{v}} \mathrm{O}_{2}$.

Then

$\mathrm{Z}=\left(\mathrm{CCO}_{2}-\mathrm{CaO}_{2}\right) /\left(\mathrm{CCO}_{2}-\mathrm{CaO}_{2}+\mathrm{Ca}-\overline{\mathrm{v}} \mathrm{O}_{2}\right)$

or

$\mathrm{CCO}_{2}-\mathrm{CaO}_{2}=\mathrm{Z} \times\left(\mathrm{CCO}_{2}-\mathrm{CaO}_{2}+\mathrm{Ca}-\overline{\mathrm{v}} \mathrm{O}_{2}\right)$.

Next, expressing oxygen contents in terms of oxygen saturation and oxygen tension, we have:

$$
\begin{gathered}
\left(\mathrm{SCO}_{2}-\mathrm{SaO}_{2}\right) \times \mathrm{Hb}+\left(\mathrm{PAO}_{2}-\mathrm{PaO}_{2}\right) \times 0.0031 \\
=\mathrm{Z} \times\left[\left(\mathrm{ScO}_{2}-\mathrm{SaO}_{2}\right) \times \mathrm{Hb}+\left(\mathrm{PAO}_{2}\right.\right. \\
\left.\left.-\mathrm{PaO}_{2}\right) \times 0.0031+\mathrm{Ca}-\overline{\mathrm{vO}} \mathrm{O}_{2}\right]
\end{gathered}
$$

or

$$
\begin{array}{r}
{\left[\mathrm{PAO}_{2}-\mathrm{PaO}_{2}\right] \times(1-\mathrm{Z}) \times 0.0031} \\
+\left[\mathrm{ScO}_{2}-\mathrm{SaO}_{2}\right] \times \mathrm{Hb} \times 1.34 \times(1-\mathrm{Z}) \\
=\mathrm{Z} \times \mathrm{Ca}-\overline{\mathrm{vO}}_{2}
\end{array}
$$

or

$$
\begin{aligned}
\mathrm{PAO}_{2}-\mathrm{PaO}_{2}= & {\left[\mathrm{Ca}-\mathrm{vO}_{2} \times \mathrm{Z}(1-\mathrm{Z})-1.34\right.} \\
& \left.\times\left(\mathrm{SćO}_{2}-\mathrm{SaO}_{2}\right) \times \mathrm{Hb}\right] / 0.003 \mathrm{I}
\end{aligned}
$$

or

$$
\begin{aligned}
& \mathrm{PaO}_{2}=\mathrm{PAO}_{2}- {\left[\mathrm{Ca}-\overline{\mathrm{vO}}_{2} \times \mathrm{Z} /(1-\mathrm{Z})-1.34\right.} \\
&\left.\times\left(\mathrm{ScO}_{2}-\mathrm{SaO}_{2}\right) \times \mathrm{Hb}\right] / 0.0031
\end{aligned}
$$

